\title{
RAIVA EM BOVINOS NA REGIÃO DE PIMENTA BUENO- RONDÔNIA, BRASIL, ESTUDO RETROSPECTIVO DE 2010 A 2014
}

\author{
BOVINE RABIES IN THE REGION OF PIMENTA BUENO-RONDÔNIA, BRAZIL, \\ RETROSPECTIOVE STUDY FROM 2010 TO 2014
}

\author{
D.O.B. OLIVEIRA ${ }^{1,2}$; V.E. SOARES ${ }^{2}$; M.A.A. BELO ${ }^{2,3 *}$
}

\section{RESUMO}

A raiva é uma enfermidade de importância mundial, por ser tratar de uma zoonose, caracterizada por causar encefalite aguda fatal. A Agência de Defesa Sanitária Agrosilvopastoril do Estado de Rondônia (IDARON) realiza as atividades de prevenção e controle dessa enfermidade no Estado. O presente trabalho teve por objetivo realizar um estudo retrospectivo dos atendimentos a suspeita de síndrome neurológica em bovinos, durante o período de 2010 a 2014, nos municípios que integram a unidade regional de supervisão de Pimenta Bueno: Cacoal, Pimenta Bueno, Espigão do Oeste, São Felipe, Ministro Andreazza e Primavera de Rondônia. As análises foram realizadas com dados gerados pela IDARON originados de 114 Form-in, destes $89,47 \%$ das investigações tiveram como suspeita inicial a ocorrência de síndrome neurológica. Em $64,91 \%$ das investigações houve envio de amostra para diagnóstico de raiva, sendo confirmados cinco casos positivos. Os resultados demonstram que bovinos com menos de 1 ano apresentaram maior número de casos com tempo de evolução clínica $\geq$ a 72 horas. Dentre os sinais clínicos mais observados na ocorrência de síndromes neurológicas em bovinos foram decúbito $64,03 \%$, incoordenação motora $41,22 \%$, movimentos de pedalagem $28,94 \%$ e opistótono $22,80 \%$. Foi realizado o georreferenciamento dos pontos de captura de morcegos e das propriedades foco para raiva, demonstrando a relação entre a ocorrência de morcegos hematófagos e os casos positivos. O tempo de evolução ao óbito e os sinais clínicos observados podem ocorrer em outras enfermidades neurológicas, além da raiva, aumentando a importância da atividade de vigilância. A ocorrência de morcegos hematófagos é um fator de risco para raiva dos herbívoros, sendo necessário aumentar as atividades de monitoramento e controle populacional destes animais, associado a políticas educacionais e a programas de vacinação dos bovinos.

PALAVRA-CHAVE: VIGILÂNCIA EPIDEMIOLÓGICA, RAIVA HERBÍVORA, MORCEGO, Desmodus rotundus.

ÁREA TEMÁTICA: Zoonoses

\footnotetext{
${ }^{1}$ Agência de Defesa Sanitária Agrosilvopastoril do Estado de Rondônia(IDARON), Pimenta Bueno/RO.

${ }^{2}$ Laboratório de Farmacologia e Toxicologia Animal, Universidade Camilo Castelo Branco, Descalvado/SP.

${ }^{3}$ Departamento de Medicina Veterinária Preventiva e Reprodução Animal, FCAV-UNESP, Jaboticabal/SP.

*maabelo@hotmail.com.
} 